\title{
Ionic Liquid Metal-Conjugates: Formation of an Imidazolium Dirhodium(II) Carboxylate
}

\section{David C. Forbes, * Samit A. Patrawala, and Kim Loan T. Tran}

University of South Alabama, Mobile, AL 36688

Fax: 251.460 .7359

Email: dforbes@jaguar1.usouthal.edu

\section{Supporting Information}

General Remarks ${ }^{1} \mathrm{H}$ NMR (300 MHz) and ${ }^{13} \mathrm{C}$ NMR (75 MHz) spectra were obtained as solutions in either $\mathrm{CDCl}_{3}$ or $\mathrm{CD}_{3} \mathrm{CN}$. Chemical shifts were reported in parts per million (ppm, $\delta$ ) and referenced to $\delta 7.27\left({ }^{1} \mathrm{H}\right.$ NMR) and $\delta 77.00\left({ }^{13} \mathrm{C}\right.$ NMR) when using $\mathrm{CDCl}_{3}$ and $\delta 1.94\left({ }^{1} \mathrm{H}\right.$ $\mathrm{NMR}$ ) and $\delta 117.63\left({ }^{13} \mathrm{C} \mathrm{NMR}\right)$ when using $\mathrm{CD}_{3} \mathrm{CN}$. Infrared spectra were recorded as a thin film using a Jasco FT/IR-4000 (ATR corrected) and were reported in wavenumbers $\left(\mathrm{cm}^{-1}\right)$. Melting points are uncorrected. Distillations were performed using a Kugelrohr ball-tube distillation apparatus. Gas chromatographic analyses were performed using an Agilent 6850 system (FID). All GC analyses were performed using a nonpolar capillary column (AT-5 (Alltech), 30m, $0.25 \mathrm{~mm} \mathrm{ID,} 0.25 \mu \mathrm{m}$ film thickness). Method parameters were $f=1.0 \mathrm{~mL} / \mathrm{min}$, $100^{\circ} \mathrm{C}(2 \mathrm{~min}), 10^{\circ} \mathrm{C} / \mathrm{min}, 275^{\circ} \mathrm{C}(10 \mathrm{~min})$. GCMS analyses were performed on a Shimadzu GC17A/QP-5000. Combustion analyses were performed by Atlantic Microlab, Inc. Atomic absorption analyses were performed by Desert Analytics. TLC analyses were performed on Whatman flexible polyester backed TLC plates with a fluorescent indicator. Detection was conducted by UV absorption ( $254 \mathrm{~nm}$ ) and charring with $10 \% \mathrm{KMnO}_{4}$ in water. Baker silica gel (47-61 microns) was used for all chromatographic separations. All chemicals used for synthetic procedures were reagent grade or better. Solutions were concentrated in vacuo with a rotary evaporator and the residue was purified using a silica gel column unless specified otherwise. 
Preparation of 1-Methyl-3-(3-ethylcarboxylate)imidazolium tetrafluoroborate (1)

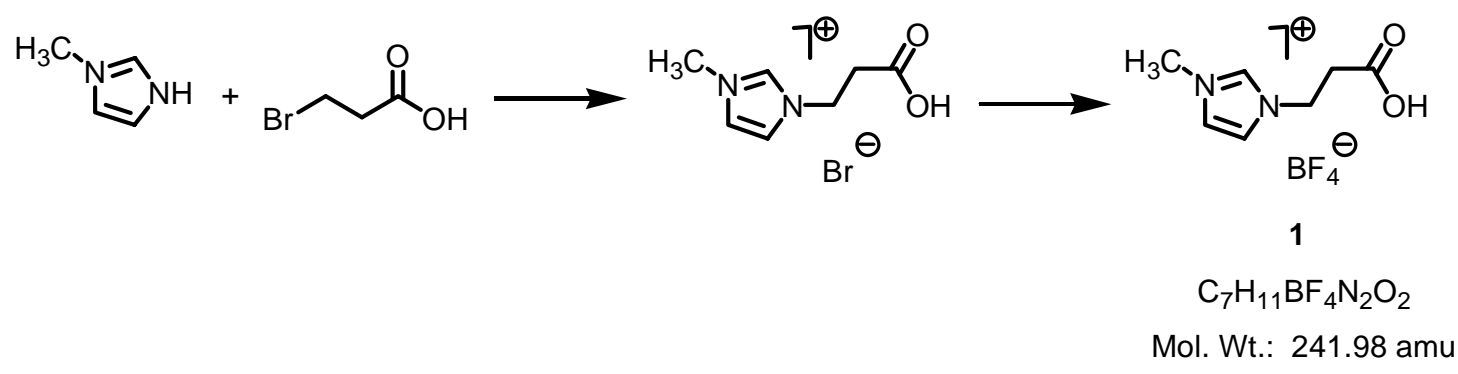

A methanolic solution consisting of equimolar quantities of 1-methylimidazole (100 mmol) and 3-bromopropionic acid was warmed to reflux and allowed to react for a period of 18h. Upon cooling to room temperature, the crude reaction mixture was treated with $\mathrm{KBF}_{4}(1.2$ equiv). Precipitation of $\mathrm{KBr}$ was observed immediately. The suspension was allowed to stir at room temperature for a period of $10 \mathrm{~h}$ at which time the $\mathrm{KBr}$ precipitant was separated from solution via gravity filtration. The filtrate was next concentrated in vacuo to afford crude imidazolium salt 1 as a pale yellow viscous oil. After washing the salt with diethyl ether $(3 \mathrm{x}$ $10.0 \mathrm{~mL}$ ), the ionic liquid was placed under vacuum ( 1 torr) for a period of $18 \mathrm{~h}$ to afford 1 methyl-3-(3-ethylcarboxylate)imidazolium tetrafluoroborate (1).

\section{Spectral Data}

${ }^{1} \mathrm{H}$ NMR (300 MHz, $\left.\mathrm{CDCl}_{3}\right) ; \delta 8.51(\mathrm{~s}, 1 \mathrm{H}), 7.41(\mathrm{dd}, J=2.0, J=1.6,1 \mathrm{H}), 7.32(\mathrm{dd}, J=1.9, J=$ 1.6, 1H), $5.77(\mathrm{br} \mathrm{s}, \mathrm{COOH}), 4.35(\mathrm{t}, J=6.1,2 \mathrm{H}), 3.81(\mathrm{~s}, 3 \mathrm{H}), 2.87(\mathrm{t}, J=4.4,2 \mathrm{H})$. ${ }^{13} \mathrm{C}$ NMR (75.5 MHz, $\left.\mathrm{CDCl}_{3}\right) ; \delta$ 171.55, 136.76, 123.59, 122.70, 45.05, 35.89, 33.55. IR (film (ATR corrected)) 3583, 3328, 3166, 3125, 1726, 1578, 1403, 1161, $1027 \mathrm{~cm}^{-1}$. 


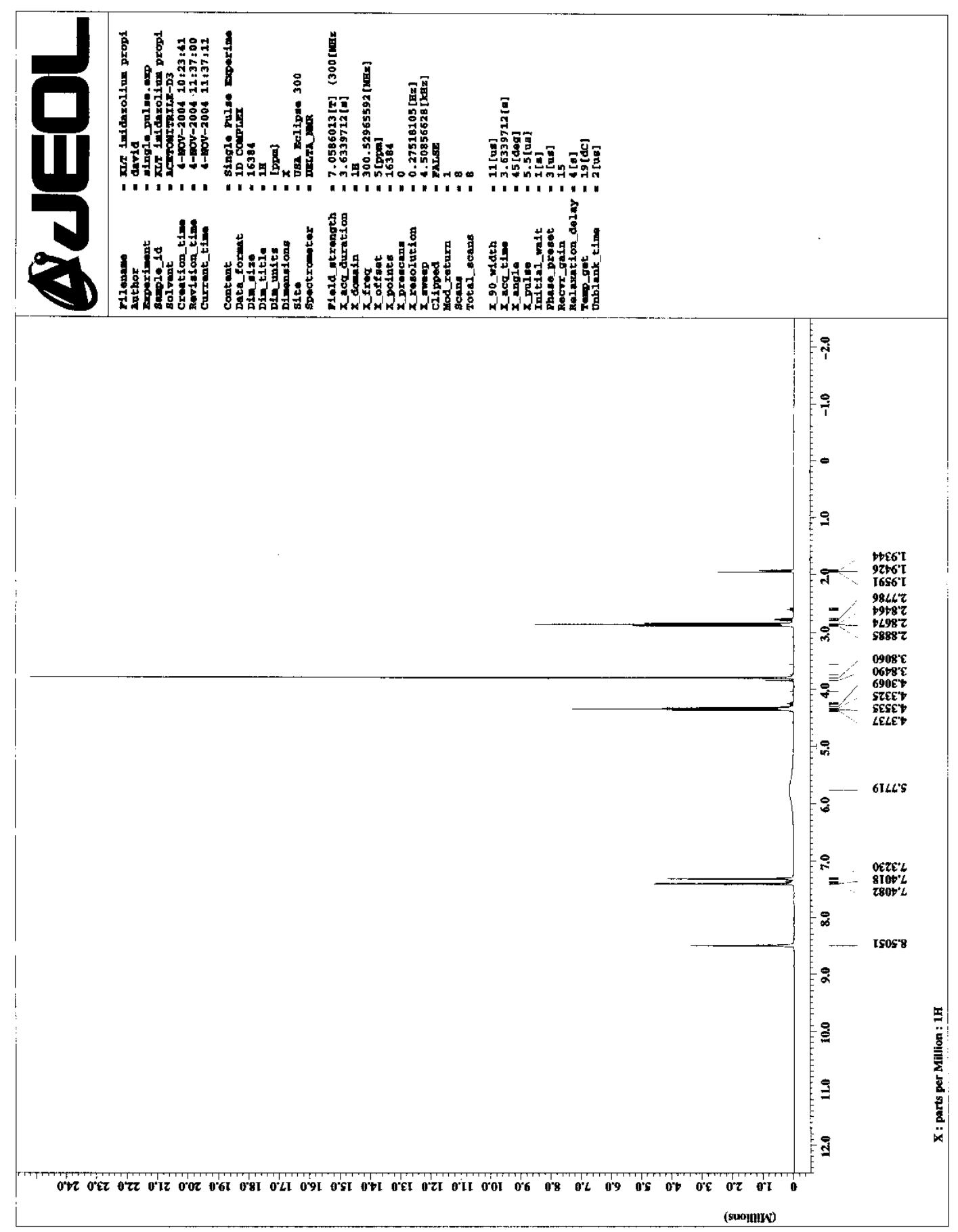

7 


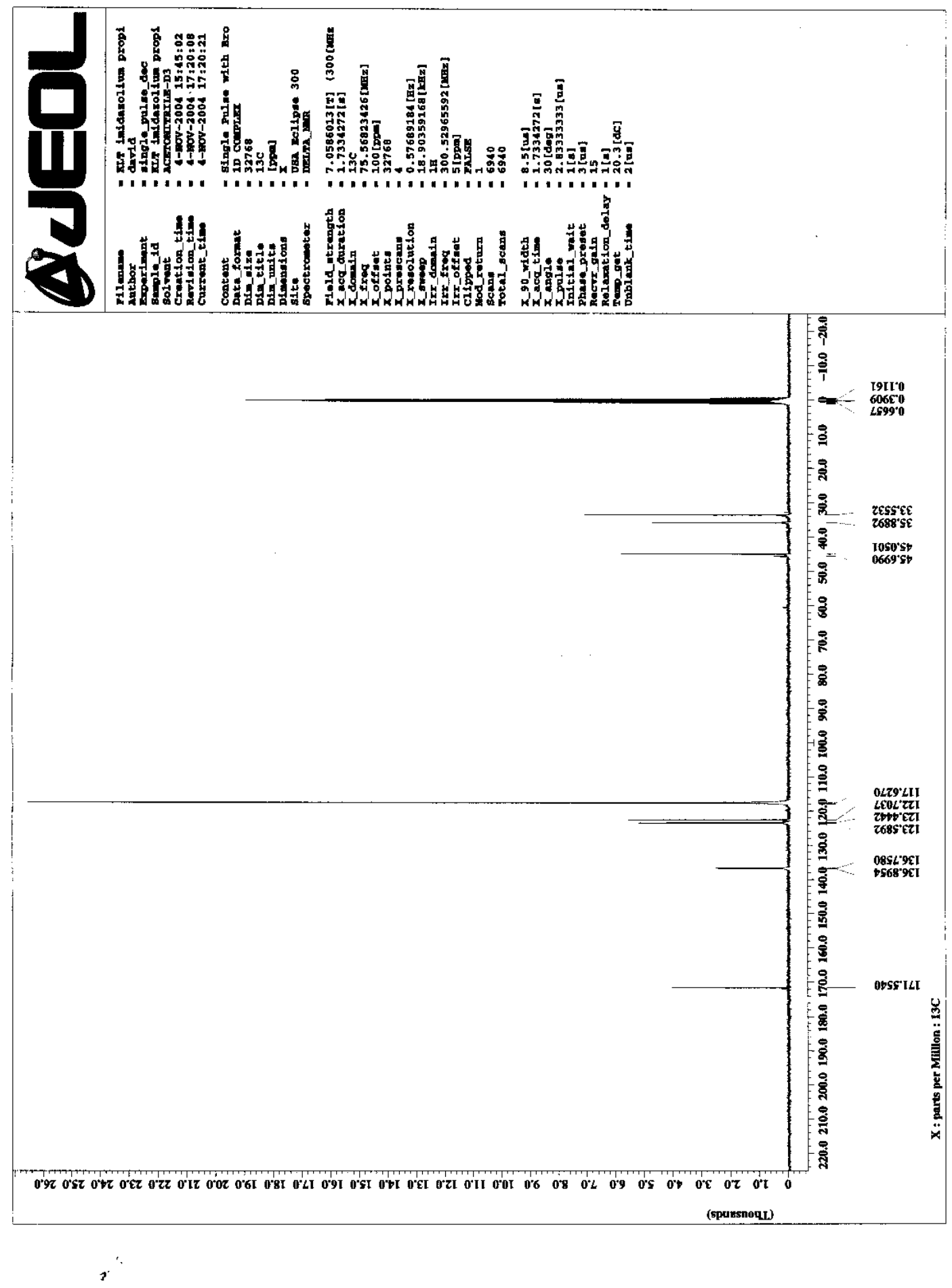


Method A:

Preparation of Dirhodium(II) Tetrakis[1-methyl-3-(3-ethylcarboxy)imidazolium tetrafluoroborate] (2)

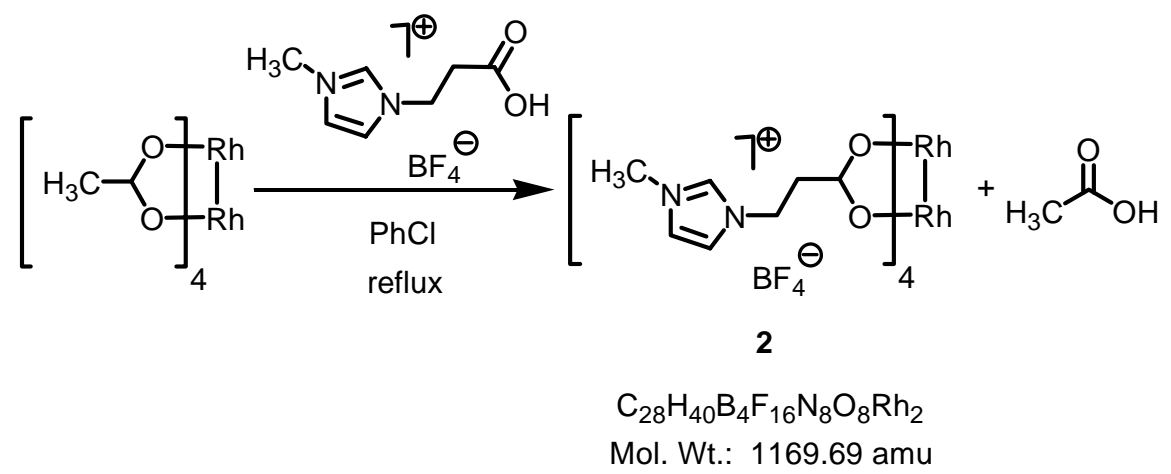

The ligated acetates of dirhodium(II) tetraacetate were replaced with imidazolium salt $\mathbf{1}$ using a Soxhlet extraction apparatus (SI Figure 1). ${ }^{1}$ The choice of solvent was chlorobenzene. While at reflux, both chlorobenzene $\left(\mathrm{bp} 132^{\circ} \mathrm{C}\right)$ and acetic acid (bp $118^{\circ} \mathrm{C}$ ) are part of the condensation/vaporization cycle. Condensation of the distillates into a thimble charged with sodium carbonate facilitates ligand exchange.

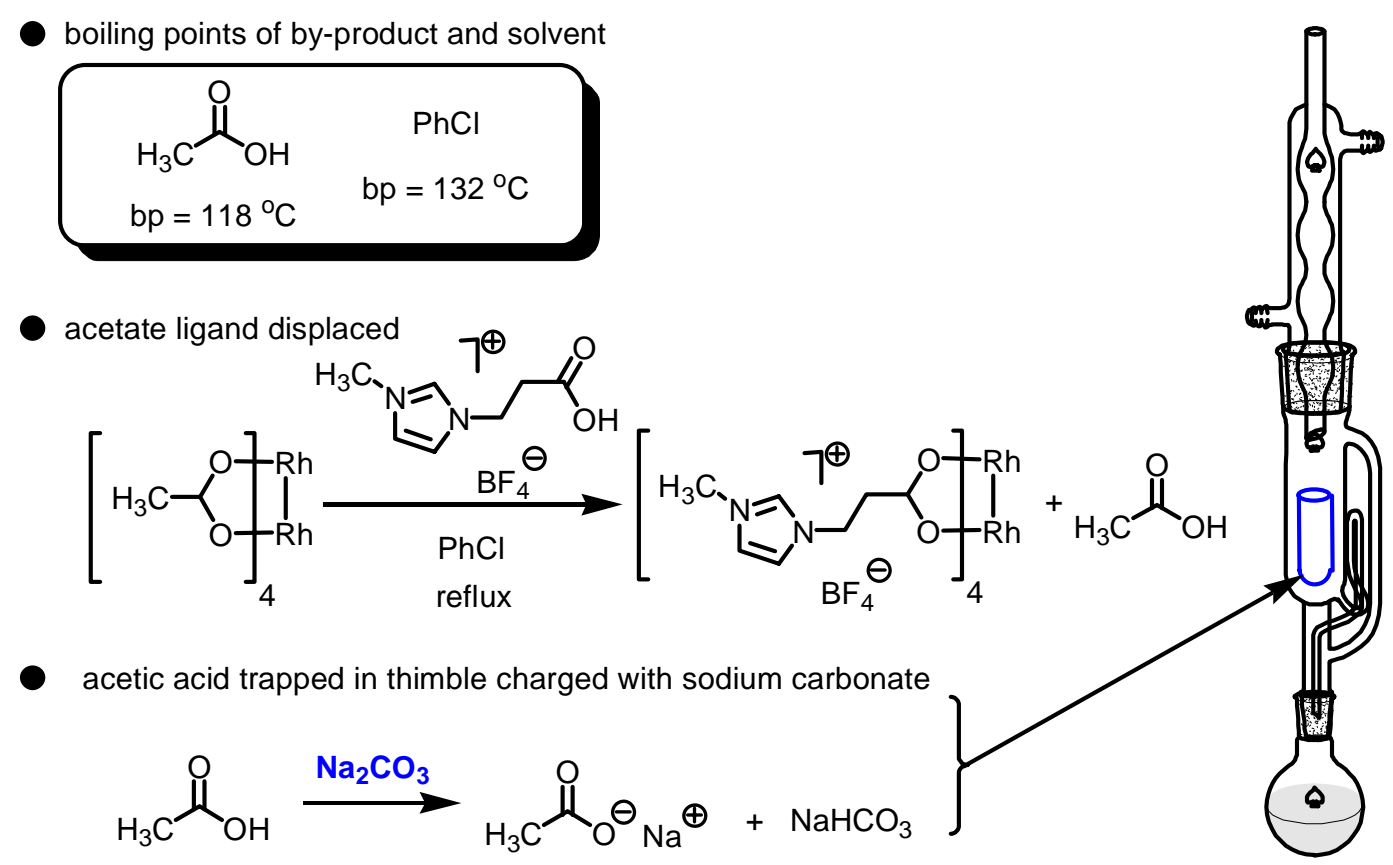

SI Figure 1. Soxhlet extraction apparatus. 
Reaction of acetic acid with the carbonate base results in formation of sodium acetate. As a salt, the acetate no longer participates in the ligand exchange equillibrium and thus effectively shifting the exchange equilibrium to the right favoring formation of dirhodium(II) tetrakis[1-methyl-3-(3-ethylcarboxy)imidazolium tetrafluoroborate] (SI Figure 2).

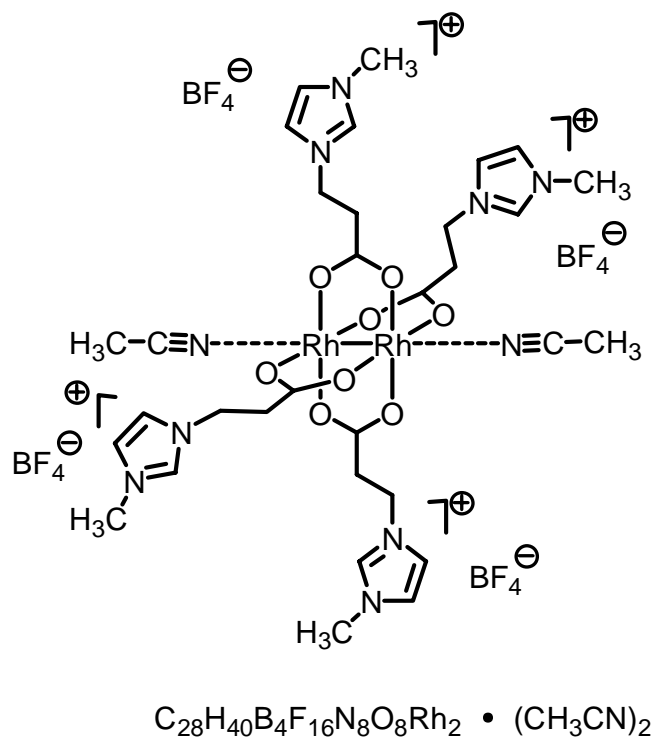

SI Figure 2. Structural representation of acetonitrile complexed dirhodium(II) tetrakis[1methyl-3-(3-ethylcarboxy)imidazolium tetrafluoroborate].

The round bottom flask of a micro-Soxhlet extraction kit (Sigma-Aldrich) was charged with 247 mg 1-methyl-3-(3-ethylcarboxylate)imidazolium tetrafluoroborate (1) (1.02 mmol) and $50 \mathrm{mg}$ dirhodium(II) tetraacetate $(0.11 \mathrm{mmol}, 0.1$ equiv). Chlorobenzene was added to fill both half of the round bottom flask and the chamber holding of a thimble charged with a mixture of sand and sodium carbonate (1:1). The thimble was fitted with glass wool in an effort to secure the base/sand mixture. The reaction mixture was externally warmed to $160^{\circ} \mathrm{C}$ and wrapped with aluminum foil to assure rapid cycling of the distillates. After a period of $6 \mathrm{~h}$, the reaction setup was allowed to cool to room temperature. The crude reaction mixture was filtered using a cotton-plugged micropipette charged with approximately one-third (v/v) Celite and rinsed with acetonitrile $(10 \mathrm{~mL})$. The filtrate was concentrated in vacuo and recrystallized by diffusion 
control (acetonitrile/methanol). NMR analysis of the crude reaction mixture revealed a $60 \%$ conversion of rhodium(II) acetate to desired product 2. Maximum recovery was observed when the crude product was dissolved in a minimum amount of acetonitrile. The reaction was performed several times and afforded on average $10 \%$ yield of the desired product 2 (dirhodium(II) tetrakis[1-methyl-3-(3-ethylcarboxy)imidazolium tetrafluoroborate]).

\section{Spectral Data}

Melting Point $233-235^{\circ} \mathrm{C}$

${ }^{1} \mathrm{H}$ NMR $\left(300 \mathrm{MHz}, \mathrm{CD}_{3} \mathrm{CN}\right) ; \delta 8.32(\mathrm{br} \mathrm{s}, 1 \mathrm{H}), 7.28(\mathrm{dd}, \mathrm{J}=1.9, \mathrm{~J}=1.6,1 \mathrm{H}), 7.20(\mathrm{dd}, \mathrm{J}=1.9$, $\mathrm{J}=1.6,1 \mathrm{H}), 4.17(\mathrm{t}, \mathrm{J}=6.6,2 \mathrm{H}), 3.82(\mathrm{~s}, 3 \mathrm{H}), 2.58(\mathrm{t}, \mathrm{J}=6.6,2 \mathrm{H})$.

${ }^{13} \mathrm{C}$ NMR $\left(75.5 \mathrm{MHz}, \mathrm{CD}_{3} \mathrm{CN}\right) ; \delta 189.78,136.95,123.31,122.51,45.08,36.51,36.00$.

IR (film (ATR corrected)) 3543, 3448, 3166, 3125, 1592, 1416, $1027 \mathrm{~cm}^{-1}$.

Combustion Analysis $\left(\mathrm{C}_{28} \mathrm{H}_{40} \mathrm{~B}_{4} \mathrm{~F}_{16} \mathrm{~N}_{8} \mathrm{O}_{8} \mathrm{Rh}_{2}\right.$ (as a $\mathrm{CH}_{3} \mathrm{CN}$ complex))

Calc'd: C, 29.76; H, 3.58; N, 10.41

Found: C, 29.95; H, 3.74; N, 10.81 
SI Table 1 provides additional spectral data supporting formation of dirhodium(II) complex 2. Both ${ }^{1} \mathrm{H}$ and ${ }^{13} \mathrm{C}$ NMR data were obtained. The data below highlights the changes in chemical shift using ${ }^{13} \mathrm{C}$ NMR spectroscopy.

SI Table 1. Representative chemical shifts in $\mathrm{CD}_{3} \mathrm{CN}$.

\begin{tabular}{ll} 
carboxylate derivative & $\begin{array}{c}\delta \text { (carbon of } \\
\text { carbonyl (ppm)) }\end{array}$ \\
\hline entry & 190 \\
3
\end{tabular}




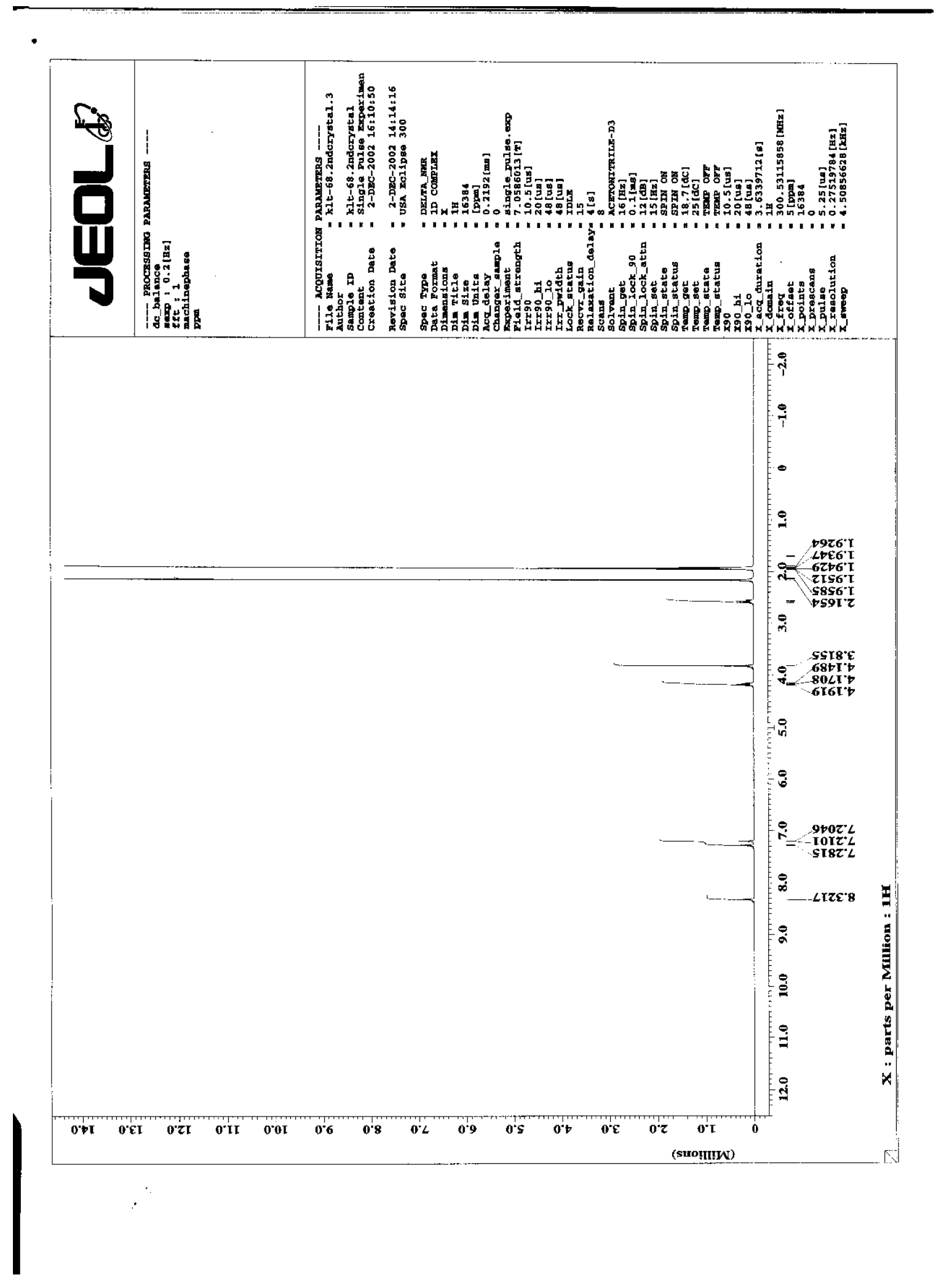




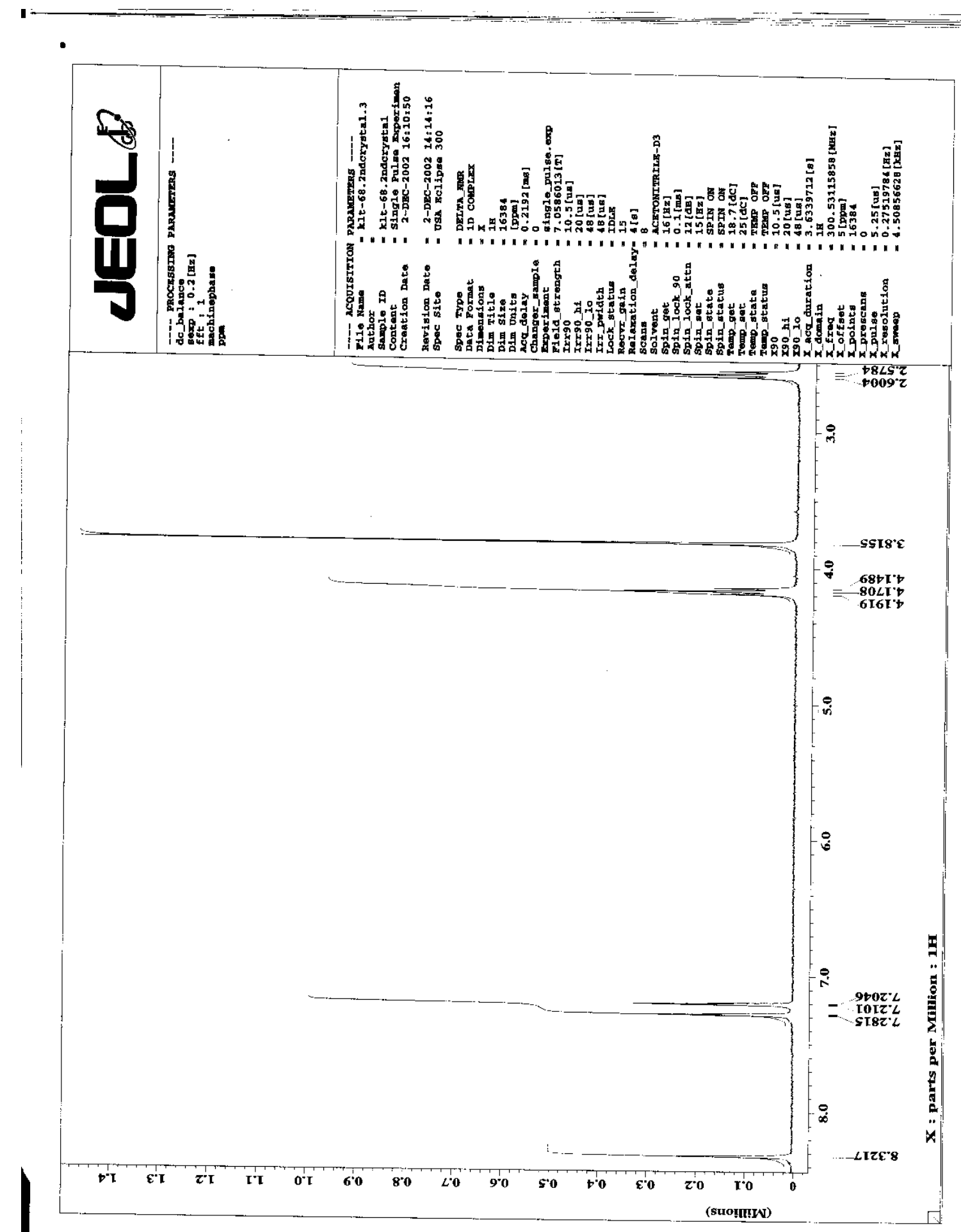




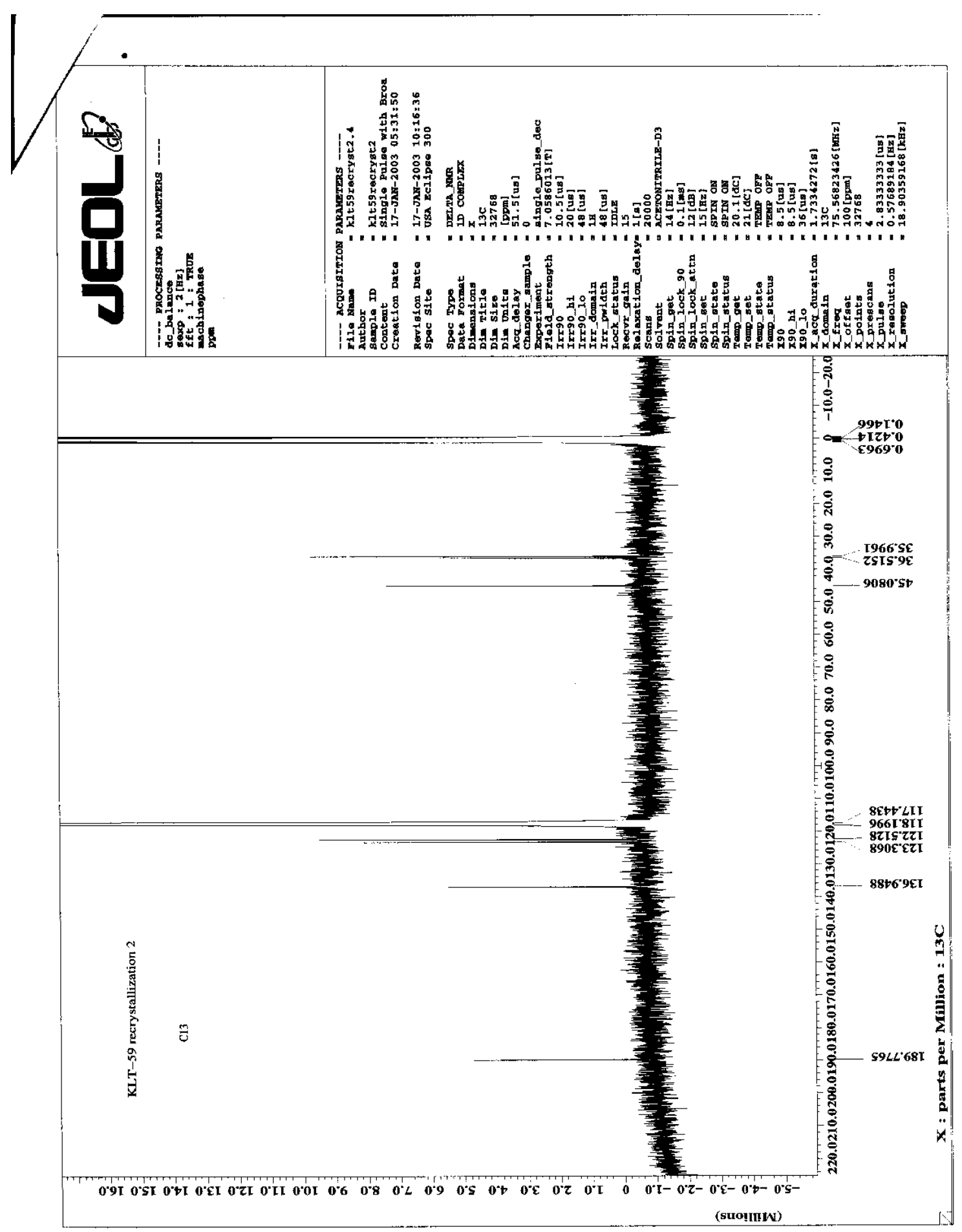




\section{Method B:}

\section{Preparation of Dirhodium(II) Tetrakis[1-methyl-3-(3-ethylcarboxy)imidazolium}

tetrafluoroborate] (2)

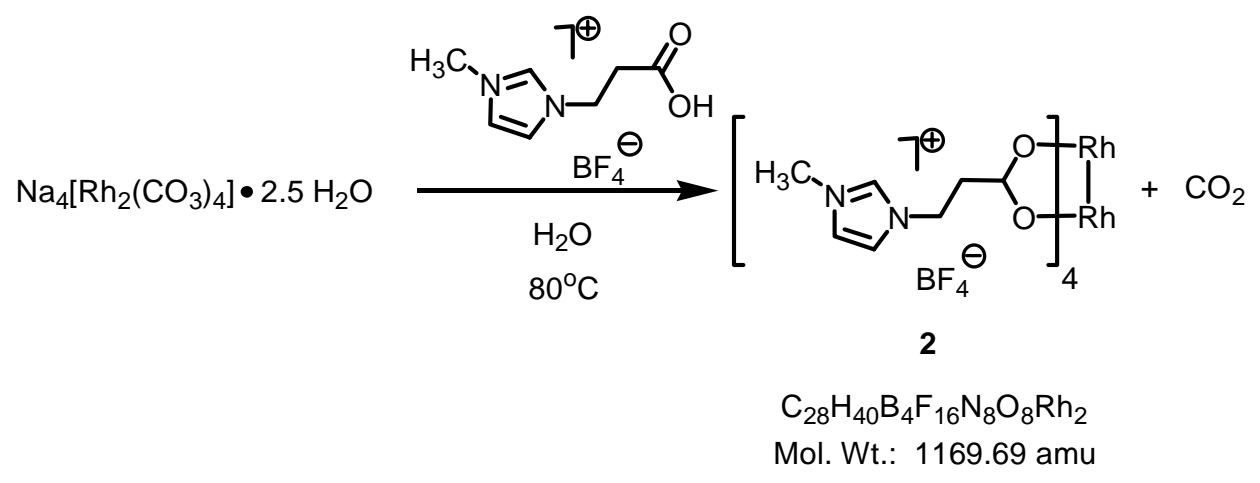

A round bottom flask was charged with $222 \mathrm{mg}$ 1-methyl-3-(3ethylcarboxylate)imidazolium tetrafluoroborate (1) (0.917 mmol, 9.9 equiv). To this system was added $3.0 \mathrm{~mL}$ of water $(18 \mathrm{M} \Omega)$. After a solution was observed a $2.0 \mathrm{~mL}$ aqueous solution containing $48 \mathrm{mg}$ tetrasodium tetrakis( $\mu$-carbonato)dirhodium hydrate $(0.09 \mathrm{mmol}, 0.1$ equiv) was added. The blue-green solution was allowed to warm to $80^{\circ} \mathrm{C}$ for a period of $8 \mathrm{~h}$. A change in color from blue-green to green was observed. The reaction was allowed to cool to room temperature. A precipitate was not observed and the reaction mixture was concentrated in vacuo. The resulting mixture was next analyzed by NMR and found to yield the desired metal-conjugate in $68 \%$ conversion. Varying the amount of IL 1, switching solvents, reaction times and temperatures did not result in an improvement. Attempts to isolate the material were not made. 


\section{Cyclopropanation Reactions}

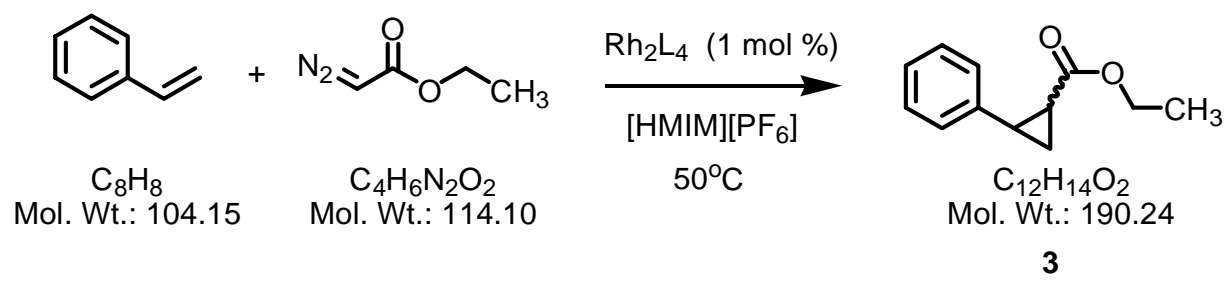

\section{Representative Procedure}

A solution of ethyl diazoacetate was added slowly (dropwise (neat)) to a warm solution $\left([\mathrm{HMIM}]\left[\mathrm{PF}_{6}\right]\left(\right.\right.$ external temperature $\left.50^{\circ} \mathrm{C}\right)$ ) consisting of styrene, dodecane and catalyst. Upon completion of addition, the reaction mixture was allowed to stir for a period of $30 \mathrm{~min}$. After cooling to room temperature, the reaction mixture was extensively washed with diethyl ether $(>5$ x $2.0 \mathrm{~mL}$ ). The rinses were collected and filtered through a cotton-plugged micropipette charged with approximately one-third (v/v) silica gel and rinsed with $\mathrm{CH}_{2} \mathrm{Cl}_{2}(10 \mathrm{~mL})$. This solution was concentrated in vacuo and the spectral data was obtained using this sample. The diastereoselectivity was obtained by GC analysis of the crude reaction mixture and confirmed by ${ }^{1} \mathrm{H}$ NMR analysis using the $\mathrm{OCH}_{2} \mathrm{CH}_{3}$ as diagnostic resonances [cis: $3.86(\mathrm{q}, J=7.1,0.4 \mathrm{~Hz}$, 2H, $\left.\mathrm{CH}_{2} \mathrm{O}\right)$; trans: $\left.4.13\left(\mathrm{q}, \mathrm{J}=7.1,1.3 \mathrm{~Hz}, 2 \mathrm{H}, \mathrm{CH}_{2} \mathrm{O}\right)\right]$. The percent yields were obtained by GC analysis and based upon an internal standard (dodecane). Mass balance of the materials obtained verified product conversion. Spectral data obtained was in agreement with previous reports. $^{2}$

\section{Cyclopropanation of Styrene using $\mathrm{Rh}_{2} \mathrm{OAc}_{4}$ in $[\mathrm{HMIM}]\left[\mathrm{PF}_{6}\right]$}

From the combination of ethyl diazoacetate $(105 \mu \mathrm{L}, 1.0 \mathrm{mmol})$, styrene $(343 \mu \mathrm{L}, 3.0 \mathrm{mmol}, 3$ equiv) and $\mathrm{Rh}_{2} \mathrm{OAc}_{4}(4.4 \mathrm{mg}, 0.01 \mathrm{mmol}, 1 \mathrm{~mol} \%)$ in $3.0 \mathrm{~mL}$ [HMIM][PF ] (0.3M) was obtained a 38:62 diastereomeric ratio of cyclopropane 3 (quantitative conversion). 


\section{Cyclopropanation of Styrene using $\mathrm{Rh}_{2} \mathrm{IL}_{4}(2)$ in $\mathrm{CH}_{2} \mathrm{Cl}_{2}$}

From the combination of ethyl diazoacetate $(105 \mu \mathrm{L}, 1.0 \mathrm{mmol})$, styrene $(343 \mu \mathrm{L}, 3.0 \mathrm{mmol}, 3$ equiv) and $\mathrm{Rh}_{2} \mathrm{IL}_{4} 2(11.7 \mathrm{mg}, 0.01 \mathrm{mmol}, 1 \mathrm{~mol} \%)$ in $3.0 \mathrm{~mL} \mathrm{CH}_{2} \mathrm{Cl}_{2}(0.3 \mathrm{M})$ was obtained a 46:54 diastereomeric ratio of cyclopropane 3 (62\% conversion).

\section{Cyclopropanation of Styrene using $\mathrm{Rh}_{2} \mathrm{IL}_{4}(2)$ in $[\mathrm{HMIM}]\left[\mathrm{PF}_{6}\right]$}

From the combination of ethyl diazoacetate ( $105 \mu \mathrm{L}, 1.0 \mathrm{mmol})$, styrene (540 $\mu \mathrm{L}, 4.75 \mathrm{mmol}, 5$ equiv) and $\mathrm{Rh}_{2} \mathrm{IL}_{4} 2$ (6 mg, $\left.0.005 \mathrm{mmol}, 0.5 \mathrm{~mol} \%\right)$ in $3.0 \mathrm{~mL}$ [HMIM][PF 6 (0.3M) was obtained a 39:61 diastereomeric ratio of cyclopropane 3 (32\% conversion). This reaction was repeated affording virtually identical results (40:60 diastereomeric ratio in 33\% conversion).

\section{Catalyst Leaching Experiments}

A $5 \mathrm{~mL}$ test-tube was charged with $0.5 \mathrm{~mL}$ [HMIM] $\left[\mathrm{PF}_{6}\right]$. Added to this sample was $15 \mathrm{mg}$ $\mathrm{Rh}_{2} \mathrm{IL}_{4}$ (2) $(25.6 \mu \mathrm{mol} \mathrm{Rh})$. A second test-tube was charged with an equivalent amount of [HMIM] $\left[\mathrm{PF}_{6}\right]$ and $5.7 \mathrm{mg} \mathrm{Rh}{ }_{2} \mathrm{OAc}_{4}(25.6 \mu \mathrm{mol} \mathrm{Rh})$. The two systems were externally warmed to $50^{\circ} \mathrm{C}$ and allowed to stir at this temperature for a period of $5 \mathrm{~min}$. After both systems were allowed to cool to room temperature, they were washed first with ethyl ether $(5 \times 2 \mathrm{~mL})$ then toluene $(5 \times 2 \mathrm{~mL})$. The combined extracts were concentrated in vacuo and submitted for analysis, atomic absorption (total rhodium content). Analysis of the $\mathrm{Rh}_{2} \mathrm{IL}_{4}$ (2) sample resulted in the recovery of $0.56 \mathrm{mg} \mathrm{Rh}\left(5.44 \mu \mathrm{mol}\right.$ (21\% leaching). Analysis of the $\mathrm{Rh}_{2} \mathrm{OAc}_{4}$ sample resulted in the recovery of $0.75 \mathrm{mg} \mathrm{Rh}(7.29 \mu \mathrm{mol}$ (29\% leaching).

\section{References:}

(1) Doyle, M. P.; McKervey M. A.; Ye, T. "Modern Catalytic Methods for Organic Synthesis with Diazo Compounds", John Wiley \& Sons, Inc., New York, 1997.

(2) Evans, D. A.; Woerpel, K. A.; Hinman, M. M.; Faul, M. M. J. Am. Chem. Soc. 1991, 113, 726. 